\title{
DESIGN OF AN INTEGRATED SILICON-PDMS CELL CARTRIDGE
}

\author{
B. Derek DeBusschere, David A. Borkholder, and Gregory T.A. Kovacs \\ Electrical Engineering, Stanford University \\ Center for Integrated Systems, CISX 202X, Stanford, CA 94305-4075
}

\begin{abstract}
The use of cell based biosensors for applications outside of the laboratory has been limited in part due to packaging issues. A design for an integrated cell cartridge that addresses the requirements of sterile fluidic interconnect and environmental regulation is presented. The device consists of a PDMS (polydimethylsiloxane) part, a glass cover, and a silicon sensing die mounted on a printed circuit board. The PDMS part forms the fluidic channels, interconnect ports, septa, and two $10 \mu \mathrm{l}$ chambers over the active sensing area. The silicon die will include integrated biological sensors and a temperature regulation system, and the glass cover seals the chambers. Electrical and fluidic connections are made simultaneously as needles pierce septa on the cartridge when it is plugged into a zeroinsertion force (ZIF) socket.

The viability of injecting suspended cells into a $10 \mu \mathrm{l}$ volume chamber and culturing them for greater than one week using a continuous flow perfusion system has been demonstrated. Initial prototypes of the cell cartridges have been assembled and cells have been cultured in the $10 \mu \mathrm{l}$ PDMS chambers.
\end{abstract}

\section{INTRODUCTION}

The potential uses of cell based biosensors range from highthroughput drug discovery to environmental monitoring [1]. Although there has been significant progress toward producing practically useful biosensors [1-5], there has been limited effort devoted to creating packaging that would enable their use outside of the laboratory. Current packaging designs range from petri dishes with patterned electrodes that are placed in an incubator [3] to elaborate sealed chambers that allow culture outside of an incubator but require laboratory facilities [6]. However, none of these address the critical issues of cell life support and reliable interconnect required in a portable system. In order to explore and overcome these issues, the development of an integrated silicon-PDMS cell cartridge has been undertaken.

The special requirements of a cell-based biosensor lead to a segregation of the system design into three components: sample fluidics, computer interface electronics, and a cell cartridge that integrates the cells, sensors, and environmental control. The fluidics and computer interface form the permanent base for the system while the cell cartridges are exchangeable. This paper will present a brief system overview and then provide more details on issues involved in the cell cartridge design.

\section{SYSTEM OVERVIEW}

A simplified fluid flow diagram of the system is shown in Figure 1(a) and the physical implementation in Figure l(b). A pump is used to continuously perfuse culture media into two separate chambers on a cell cartridge. The sample under test is mixed with the input stream of one of the chambers, while the other chamber acts as a control. Both the control and test chambers experience

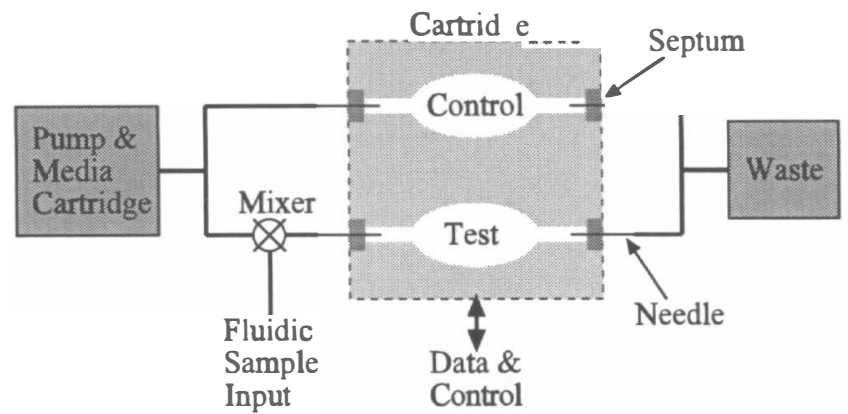

(a)

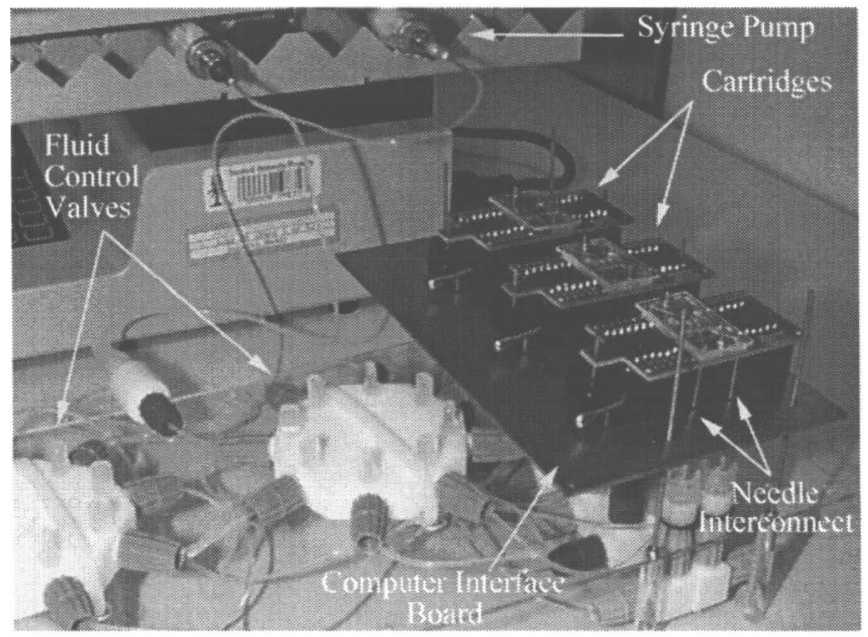

(b)

Figure 1. (a) Simplified diagram of system showing fluid flow paths. The two chambers of the cartridge are labeled "Test" and "Control." (b) The current implementation uses a syringe pump and supports three cartridges in parallel. The computer interface board is removeable, allowing the entire fluidics system to be sterilized by autoclaving.

the same temperature and base media, allowing for the removal of those variables from the sensor's output. The carridge design has an integrated temperature regulation system and integrated sensors that monitor cellular activity.

Fluidic interconnect is one of the more difficult challenges for a cell based biosensor used outside of the laboratory since sterility must be maintained and the introduction of air bubbles must be avoided. Contamination of the culture by fast growing microorganisms, such as bacteria, will overwhelm the sensing cells. Excessive mechanical forces due to air bubbles moving through a microchamber can physically damage cells and overcome cell to substrate adhesion. The interconnect approach used in this design are needles that pierce septa (resealable membranes) on the cartridge. Needles and septa proved to be a simple and effective way to create a bubble-free fluidic connection that has a high probability of remaining sterile. Electrical and fluidic connections are made simultaneously 
as the cartridge is inserted into a ZIF socket, simplifying use and handling and allowing the cell cartridges to be easily exchanged.

Cells will be seeded into the assembled and sterilized carridge chambers by injection through the septa. This approach allows for the possibility of chamber seeding to occur outside of a sterile hood. For remote applications, cells could be transported and stored while in suspension using hibernation media or cryogenic means $[\mathbf{7 , 8}]$. At the location of use, the cells could be revived and injected into the cartridges without requiring a sterile hood. After the cells are given time to attach, spread, and stabilize, the cartridges would be ready to plug into the sensing system and sample flow could begin.

\section{CELLULAR REQUIREMENTS}

The cell cartridge must provide a hospitable environment for the cells. The major environmental properties that must be controlled for cell culture are the incubation temperature, the substrate material, the media, and the gas phase mixture [9]. The optimal incubation temperature for a cell culture varies according to cell type and origin, but most mammalian cell lines will grow satisfactorily at $37^{\circ} \mathrm{C}$. Cells can withstand considerable temperature drops for short periods of times and can be stored for up to a month at $4{ }^{\circ} \mathrm{C}$ using hibernation media [7] or for years at cryogenic temperatures [8]. Although temperatures a few degrees below optimal do not affect viability, cells can not tolerate higher temperatures and will die rapidly at temperatures above $40^{\circ} \mathrm{C}$. Thus, it is important to regulate the temperature in a manner that avoids overheating the cells at local hot spots. Since both the metabolism and growth rate of cells are dependent on temperature, consistency is more important than accuracy, and regulation should be maintained within $\pm 0.5^{\circ} \mathrm{C}$ [9]. Temperature uniformity is particularly important in biosensor systems that rely on cellular metabolism as the transducer mechanism.

Most mammalian cells are anchorage dependent, that is, they require attachment to a substrate in order to survive and grow. Cells do not attach to the substrate directly but to extracellular matrix proteins that are either contained in the culture media or excreted by the cells themselves. Surfaces that do not bind well with these proteins, such as uncharged hydrophobic ones, will not support anchorage dependent cells. An additional important requirement of the substrate and of all materials that contact the culture media is biocompatibility. Biocompatible materials do not leech or vent significant amounts of toxins over the duration of the sensor's lifetime.

The two most significant constituents of the gas phase are oxygen and carbon dioxide. Oxygen is necessary for the oxidative metabolism of eukaryotic cells and is utilized at the rate of approximately 2 to $10 \mathrm{pg} /$ cell/hr [10]. Since the solubility of oxygen in culture media is approximately $8 \mathrm{ng} / \mu \mathrm{l}$ at $37^{\circ} \mathrm{C}$, a cell culture of 1,000 cells will consume all of the dissolved oxygen in $1 \mu \mathrm{l}$ of culture media in approximately 1 hour. Carbon dioxide is necessary only indirectly as it is involved in the bicarbonate buffer system. A lack of carbon dioxide results in a depletion of $\mathrm{HCO}_{3}{ }^{-}$in the media which is detrimental to cellular health. Most cell cultures are incubated in an atmosphere of 5 to $10 \% \mathrm{CO}_{2}$ in air that equilibrates with the bicarbonate buffer in the media at the proper $\mathrm{pH}$ for the cells.

The culture medium provides the nutrients (inorganic salts, amino acids, glucose, and in many cell lines, serum) necessary for cell growth and survival. In addition to the nutrients, two important properties of the media are its $\mathrm{pH}$ and osmolality. The $\mathrm{CO}_{2}$ gas phase regulates the $\mathrm{pH}$ through the bicarbonate buffer system as described above to a typical value of approximately 7.4. The impor-

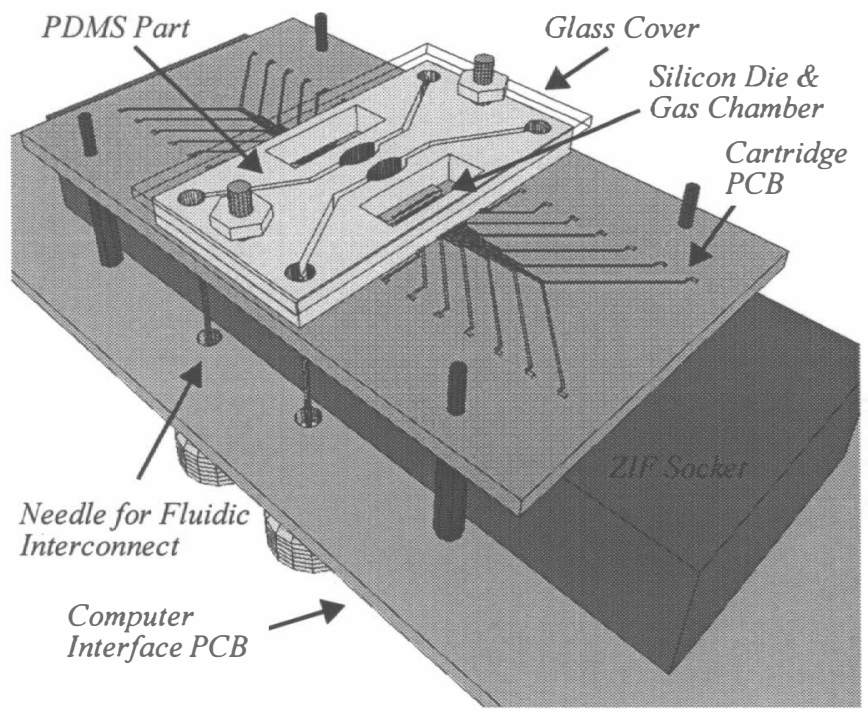

(a)

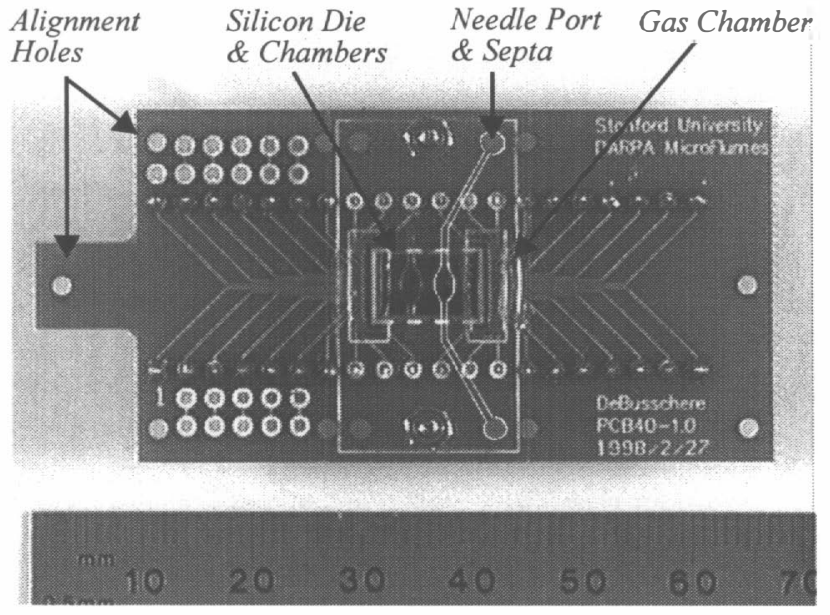

(b)

Figure 2. (a) CAD design of the cell cartridge. The silicon die is mounted directly on the PCB and enclosed on the top and sides (except for exposed bond pad areas) by the PDMS part. As the cartridge is lowered into the ZIF socket, the needles pierce septa to form the fluidic interconnect. (b) Top view of cell cartridge prototype. The $6 \times 9 \mathrm{~mm}$ silicon die can be seen as the dark rectangle beneath the two oval chambers. The $0.5 \mathrm{~mm}$ wide fluid channels on the right side have been highlighted in white.

tance of osmolality arises in sample injection, as care must be taken to adjust the osmotic strength of the sample to limit osmotic stresses across the cell membrane. Although cells are tolerant of osmolalities in the range of 260 to $320 \mathrm{mOsm} / \mathrm{kg}$, consistency to within $\pm 10 \mathrm{mOsm} / \mathrm{kg}$ should be maintained to avoid interfering with cellular function [9].

\section{CARTRIDGE DESIGN.}

Important design issues for the cell cartridge are satisfying the cellular requirements, creating reliable electrical and fluidic connections, and integrating useful biological sensors to monitor cellular activity. The cartridge design consists of a PDMS part, a glass cover, and a silicon sensing die mounted on a printed circuit 
board (Figure 2). The PDMS part forms the fluidic channels, interconnect ports, septa, and two $10 \mu \mathrm{l}$ chambers over the active sensing area. The silicon die contains microelectrodes for action potential and impedance measurements, temperature sensors, thinfilm $\mathrm{pH}$ sensors, and a temperature regulator. The glass cover seals the chambers and allows the additional use of visual and fluorescence microscopy to monitor cellular activity.

The printed circuit board acts as rigid mounting structure and forms the electrical interconnect from the silicon die to the ZIF socket. Soft gold was used for the traces in order to allow bond pad wire connections to be made to them. The PCB also contains alignment holes for guide posts that ensure that the fluidic system needles contact only the septa during cartridge removal and insertion.

The properties of PDMS (Dow Corning Sylgard 184 Silicone Elastomer) make it a nearly ideal material for this application. PDMS is biocompatible and its strong hydrophobicity prevents cellular material from easily adhering to it [11]. It can withstand a broad temperature range $\left(-55^{\circ} \mathrm{C}\right.$ to $\left.130^{\circ} \mathrm{C}\right)$ while maintaining its soft, elastomeric properties which are useful in both acting as a gasket to form a seal with the silicon die and glass cover and acting as septa for the fluidic connections. Unlike most silicones, PDMS absorbs less than $0.1 \%$ water, and sterilization can be accomplished using Cobalt 60 or autoclaving. As can be seen in Figure 2, PDMS is very transparent even at thicknesses greater than one millimeter. Another very important property is its high gas permeability to oxygen and carbon dioxide $\left(7\right.$ and $35 \times 10^{-15} \mathrm{~m}^{3}(\mathrm{STP}) \cdot \mathrm{m} /\left(\mathrm{m}^{2} \cdot \mathrm{s} \bullet \mathrm{Pa}\right)$, respectively) [12]. Thus, with only one material, PDMS can be used to form the fluidic channels and chambers, the septa, the gasket seal, and the permeable membrane while providing optical access.

The standard cell substrates used in traditional cell culture are glass and single-use plastics such as polystyrene which have good optical properties and favorable surface charges. In the application of silicon based biological sensors, the variety of possible cell substrates is constrained by the thin films available in the integrated circuit process. Potential candidates are silicon dioxide, silicon nitride, silicon carbide, and organics such as photoresist and polyimide. The most important properties of the thin film are biocompatibility and a favorable surface charge that promotes cellular adherence. Other factors, such as the ability to block mobile ions in the culture media from the integrated circuits below, low dielectric constant to minimize electrical parasitics to the wafer substrate below, and ease of cleaning and sterilization, are also important to consider. With the exception of a low dielectric constant, silicon nitride has all of these favorable properties and has been used successfully in earlier designs [5].

Calculations predict heater power consumption will be less than $50 \mathrm{~mW}$, with the majority of the power loss due to conduction through the PCB and the bond wires and not due to heating the media. This power consumption level should not create a temperature gradient of more than $0.15^{\circ} \mathrm{C}$ across the die beneath the chambers, and these calculations were used to justify the assumption of an isothermal silicon die for the computer simulation shown in Figure 3(a). This simulation was performed to verify that room temperature media will reach the proper temperature before it contacts the cells. All simulations assume a flow rate of $10 \mu \mathrm{l} / \mathrm{min}$. Although this rate is approximately 10 to 100 times the required rate to supply sufficient oxygen to the cells, these rates may be desirable during testing for biological agents. Assumptions made in the simulation include an isothermal silicon die at $37^{\circ} \mathrm{C}$, room temperature media at $20^{\circ} \mathrm{C}$, and a power loss of $25 \mathrm{~W} /\left(\mathrm{m}^{2} \cdot \mathrm{K}\right)$ from the materials to the surrounding air. The simulated worst case required power consumption to maintain the cells at the proper temperature was less
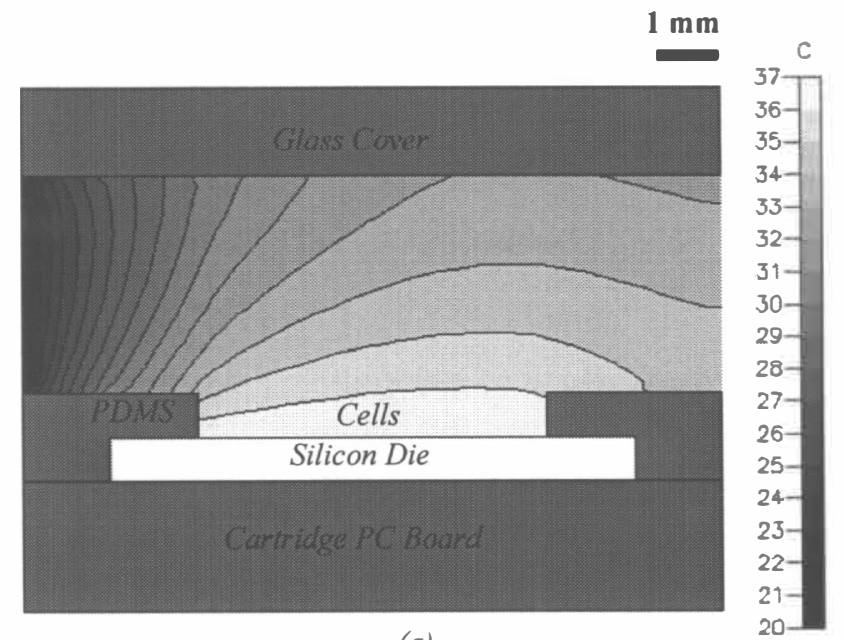

(a)

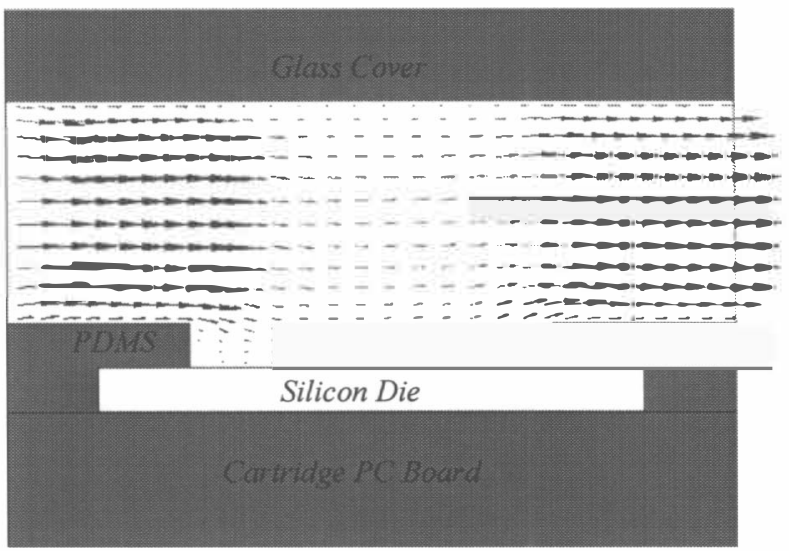

(b)

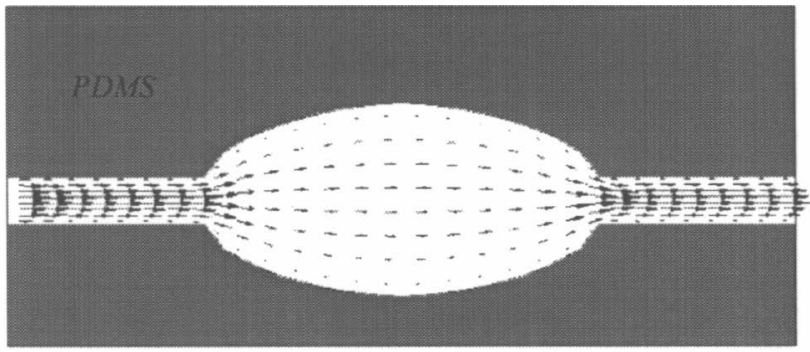

(c)

Figure 3. Computer simulations (software tool from the CFD Research Company) of temperature distribution and fluid flow through the microincubator. All assume a flow rate of $10 \mu \mathrm{L} / \mathrm{min}$ from left to right. (a) The side view of the temperature profile shows that room temperature media is heated to the required $37^{\circ} \mathrm{C}$ above the cells. Side view (b) and top view (c) of fluid flow velocity. Larger arrows indicate higher fluid velocity.

than $100 \mathrm{~mW}$. It is important to remember that the incoming media needs to have been equilibrated at $37^{\circ} \mathrm{C}$ with the proper gas phase in order to prevent the formation of air bubbles when the media is heated in the chambers.

The simulations shown in Figures 3(b) and 3(c) were performed in order to visualize the fluid flow. The simulations indicate that the $0.5 \mathrm{~mm}$ high protective shelf formed by the PDMS overlapping the silicon die will provide some protection from shear forces 
due to strong currents. Even without flow mixing, the shelf is thin enough that diffusion should allow samples to reach the cells.

Although the nutrient supply in the chamber is sufficient to last a week without replenishment, the oxygen supply in a sealed chamber will typically last less than a day. The substrate area of the $10 \mu \mathrm{l}$ chamber is approximately $6.5 \mathrm{~mm}^{2}$ which will typicallymsupport a cell density of up to about 5,000 cells (typical plating densities range from 100 to 1,000 cells $/ \mathrm{mm}^{2}$ ). The amount of dissolved oxygen in $10 \mu \mathrm{l}$ of chamber will support these cells for less than two hours; thus, either a gas permeable membrane must exist or media must be continuously perfused to provide oxygen. The oxygen requirement does not pose a problem during testing since a flow perfusion system is required for sample introduction. However, for incubation periods, it would be preferable to not require an active fluidics system. Fortunately, with the proper chamber design, the high gas permeability of PDMS will provide sufficient oxygen to the cells, but the high permeability to carbon dioxide can also disrupt the $\mathrm{CO}_{2}$ gas phase and alter the $\mathrm{pH}$ of the media. In order to take advantage of the gas permeability, a gas reservoir with the proper gas mixture must be in contact with the membrane; so, the design incorporates two gas chambers (Figure 2(a)) over the silicon die's bond pads. These chambers will be filled (by injection) with the proper $\mathrm{CO}_{2}$ in air mixture to control the $\mathrm{pH}$ and provide enough oxygen for the cells to survive several days. The sides of the PDMS exterior need to be coated with a $\mathrm{CO}_{2}$ impermeable material in order to preserve the injected gas mixture.

Several experiments have been performed in order to test the cartridge design. Cell adhesion properties have been tested on silicon oxide, silicon nitride, silicon carbide, and on a LPCVD PTFElike thin film. Silicon nitride and silicon carbide both support cell culture quite well, and the hydrophobic PTFE-like surface inhibits cellular adhesion allowing for the possibility for photolithographic patterning of cell location. The viability of injecting suspended cells into a gas impermeable $10 \mu \mathrm{l}$ volume chamber and culturing them for greater than one week using a continuous flow perfusion system has been demonstrated with NG-108 (neuroblastoma $x$ glioma hybrid) cells. The needle and septa interconnect system worked well outside of a sterile hood, allowing multiple connections as media sources were exchanged. Cells have been cultured in the PDMS chamber discussed in this paper, but since the integrated circuit die has not yet been fabricated, an external heater was necessary.

\section{INTEGRATED CIRCUITS AND SENSORS}

The $6 \times 9 \mathrm{~mm}$ floorplan for the silicon die is shown in Figure 4. A smaller $2.5 \times 2.5 \mathrm{~mm}$ test die with the identical subcircuits is in fabrication, and upon verification of correct circuit functionality, devices with this larger floorplan will be fabricated. The black outline of the PDMS part shows the chamber locations and that the bondpads are uncovered to allow for wire bonding to the PCB. Each chamber has three large pseudo-reference electrodes, four arrays of sixteen microelectrodes each, multiple $\mathrm{pH}$ and temperature sensors, and nine sixteen channel multiplexers. Digital logic, which uses a three wire serial interface, controls the multiplexers.

The temperature regulation system is located in the center of the die. The system consists of a diode temperature sensor, a control amplifier, and a MOSFET heater connected in a closed loop system (Figure 5(a)). The temperature control reference voltage will be set with an off-chip resistor, and the control loop will be compensated with an off-chip capacitor. The heater surrounds the temperature

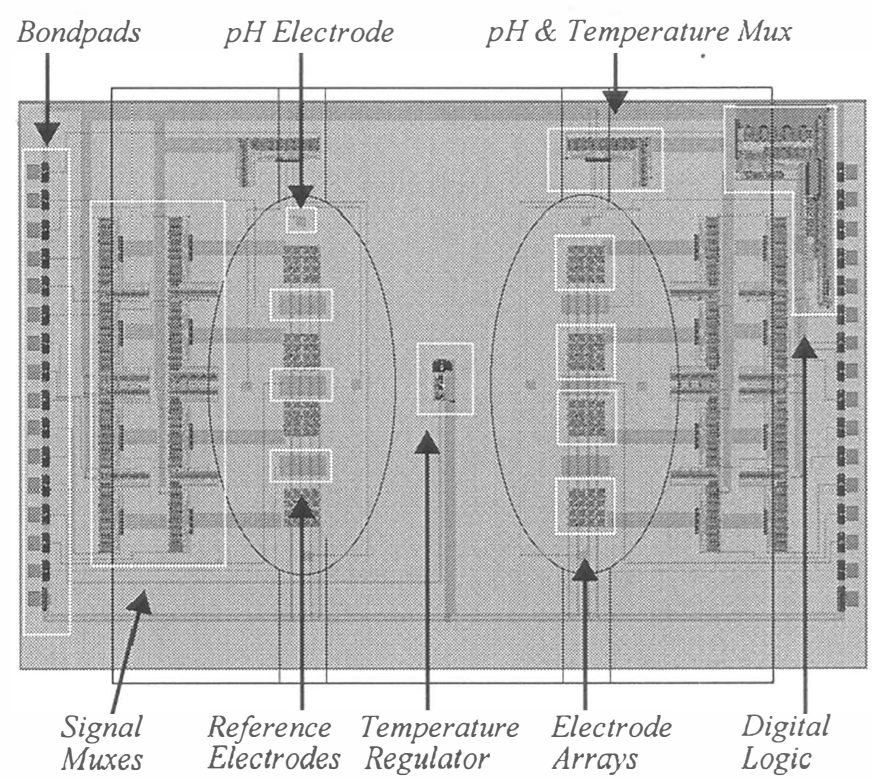

Figure 4. Circuit layout with analog amplifiers, temperature regulator, and digital logic. The PDMS part is outlined in black above the layout to indicate chamber positions.
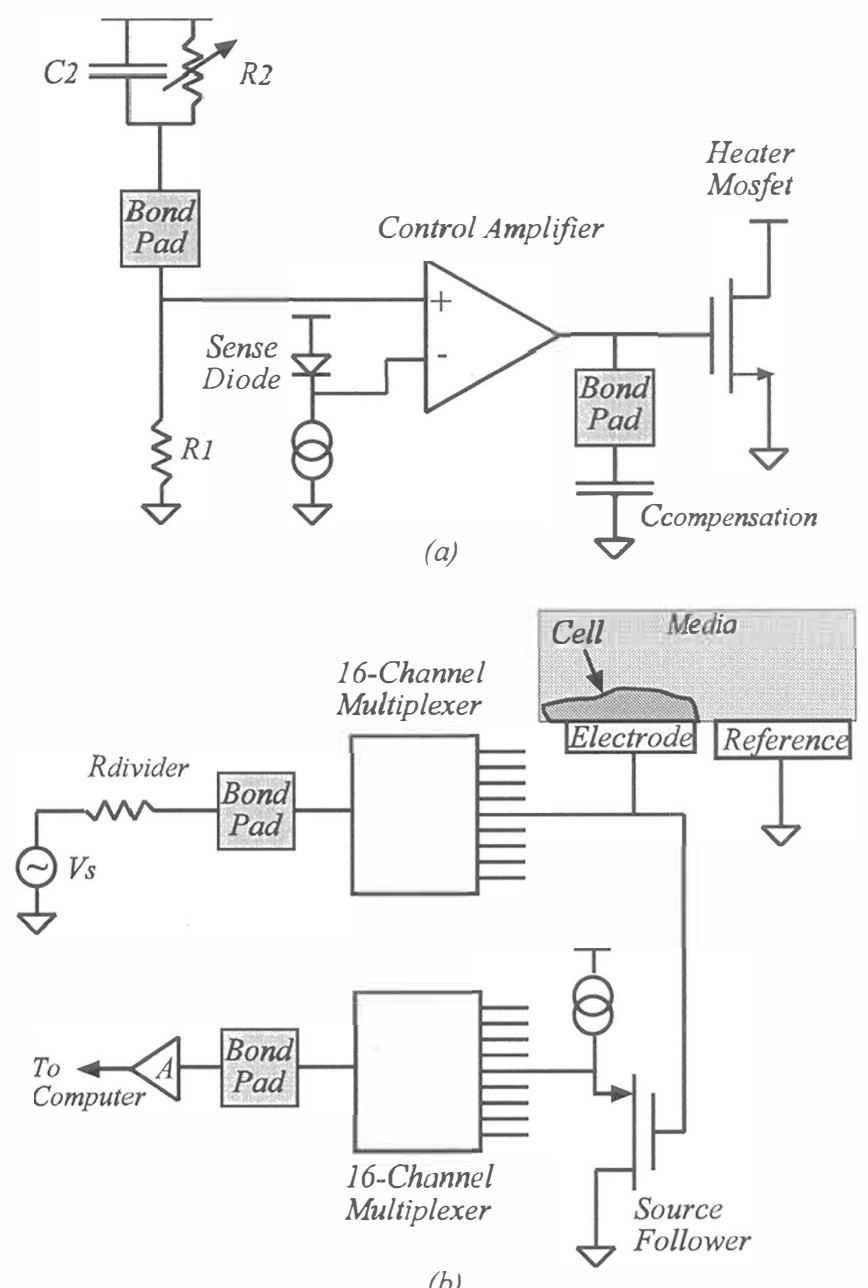

(b)

Figure 5. Block diagrams of circuits planned for cartridge chip. (a) The temperature regulation system. (b) The analog signal paths for the microelectrode arrays. 
sensor at a distance of less than 20 microns in order to maximize the bandwidth of the thermal pole. The close proximity of the sensor should also prevent any local overheating due to temperature gradients from the heater to the sensor.

The primary sensors for the cell cartridge are platinized gold microelectrodes. Each microelectrode has a connection to two separate multiplexers (Figure 5(b)). One connection is direct to a multiplexer (for platinization, impedance measurements, and unbuffered action potential measurements), while the other connection goes to a low-noise source follower whose output is routed through the second multiplexer (for buffered action potential measurements). This allows simultaneous action potential recordings from four buffered and four unbuffered microelectrodes per chamber. The impedance of the cell-electrode interface has also been shown to be an indicator of biological activity [3]. During impedance measurements, the AC signal $V_{S}$ is voltage divided by the combination of $R_{\text {divider }}$ and the impedance of the cell-electrode interface. The pseudo-reference electrodes, approximately 1,000 times the area of the sensing microelectrodes, will be used to hold the solution at a near constant potential during the impedance and action potential measurements.

Two additional multiplexers provide analog channels for monitoring temperature and $\mathrm{pH}$ across the chambers. Diode temperature sensors will be distributed across the die to monitor any temperature gradients due to heating losses. A pH sensor will allow the detection of shifts in $\mathrm{pH}$ due to incorrect gas phase, improper sample preparation, or contamination. When continuous perfusion is not used, the $\mathrm{pH}$ will also indicate when the gas mixture in the gas chambers needs to be replenished. The lack of a true reference electrode in the microchamber requires the use of differential sensing between three electrodes to measure $\mathrm{pH}$ [13]. In this method, two $\mathrm{pH}$ sensitive thin-film electrodes (or potentially ISFETs) with different output slopes are measured differentially against a noble metal pseudo-reference electrode. The output of this method eliminates the requirement of measuring the actual potential of the electrolyte. The anticipated method of forming the $\mathrm{pH}$ sensitive electrodes will be by electrochemical deposition of thin films, such as iridium oxide, onto gold microelectrodes [14]

\section{SUMMARY}

The requirements to create a fieldable cell based sensor are discussed and the current design solution outlined. Prototypes have been constructed, materials have been tested, signals have been recorded from electrodes, and cells have been cultured in small volumes. Circuit designs, including amplifiers, source followers, digital control circuits, analog multiplexers. and a temperature regulation system, have been completed and are in fabrication.

\section{ACKNOWLEDGMENTS}

Dr. Dominik Jaeggi provided invaluable and greatly appreciated assistance with the modeling simulations.

DeBusschere is supported by a NDSEG Research Fellowship and project funding was provided by the DARPA MicroFlumes Program (Contract Number: N66001-96-C-8631).

\section{REFERENCES}

1. L. Bousse, "Whole Cell Biosensors", Sensors and Actuators B (Chemical), vol. B34(1-3), 270-5 (1996).

2. G. W. Gross, B. K. Rhoades, H. M. E. Azzazy, and M. Wu, "The Use of Neuronal Networks on Multielectrode Arrays as Biosensors", Biosensors \& Bioelectronics, vol. 10(6-7), 553-67 (1995).

3. C. R. Keese and I. Giaever, "A Biosensor that Monitors Cell Morphology with Electric Fields", IEEE Engineering in Medicine and Biology, vol. 13(3), 402-8 (June/July 1994).

4. H. M. McConnell, J. C. Owicki, J. W. Parce, D. L. Miller, G. T. Baxter, H. G. Wada, and S. Pitchford, "The Cytosensor Microphysiometer: Biological Applications of Silicon Technology", Science, vol. 257(5078), 1906-12 (25 September 1992).

5. D. A. Borkholder, B. D. DeBusschere, and G. T. A. Kovacs, "An Approach to the Classification of Unknown Biological Agents With Cell Based Sensors", Technical digest of the 1998 Solid-State Sensor and Actuator Workshop, Hilton Head Island, SC, 6/7-6/11, Transducer Research Foundation, Cleveland (1998).

6. G. W. Gross and F. U. Schwalm, "A Closed Flow Chamber for Long-term Multichannel Recording and Optical Monitoring", Journal of Neuroscience Methods, vol. 52, 73-85 (1994).

7. G. J. Brewer and P. J. Price, "Viable Cultured Neurons in Ambient Carbon Dioxide and Hibernation Storage for a Month", $\mathrm{Neu}$ roreport, vol. 7(9), 1509-1512(1996).

8. J. Hornung, T. Muller, and G. Fuhr, "Cryopreservation of Anchorage-Dependent Mammalian Cells Fixed to Structured Glass and Silicon Substrates”, Cryobiology, vol. 33(2), 260-270 (1996).

9. R. I. Freshney, "Culture of Animal Cells: A Manual of Basic Technique”, 3rd ed., Wiley-Liss, Inc., New York, NY (1994).

10. R. E. Spier and B. Griffiths, "An Examination of the Concepts Germane to the Oxygenation of Cultured Animal Cells", Developments in Biological Standards, vol. 55, 81-92 (1982).

11. A. J. You, R. J. Jackman, G. M. Whitesides, and S. L. Schreiber, "A Miniaturized Arrayed Assay Format for Detecting Small Molecule-Protein Interactions in Cells", Chemistry \& Biology, vol. 4(12), 969-975 (1997).

12. S. A. Stern, V. M. Shah, and B. J. Hardy, "Structure-Permeability Relationships in Silicone Polymers", Journal of Polymer Science, Polymer Physics Edition, vol. 25, 1263-1298 (1987).

13. H. Wong and M. H. White, "A CMOS-Integrated 'ISFET-Operational Amplifier' Chemical Sensor Employing Differential Sensing". IEEE Transactions on Electron Devices, vol. 36(3), 479-487 (1989).

14. K. Pasztor, A. Sekiguchi, N. Shimo, N. Kitamura, and H. Masuhara, "Iridium Oxide-based Microelectrochemical Transistors for pH Sensing", Sensors and Actuators B (Chemical), vol. B12(3), 225-230 (1993). 